\title{
GLOBAL STRENGTH ANALYSIS FOR A SPLIT HOPPER BARGE SUBJECT TO HEAD EQUIVALENT DESIGN WAVE
}

\author{
Liviu Andrei Moise \\ "Dunarea de Jos" University of Galati, \\ Faculty of Naval Architecture, Galati, Domneasca \\ Street, No. 47, 800008, Romania, \\ E-mail: liviu.moise@glo-marine.com

\section{Leonard Domnișoru} \\ "Dunarea de Jos" University of Galati, \\ Faculty of Naval Architecture, Galati, Domneasca \\ Street, No. 47, 800008, Romania, \\ E-mail: leonard.domnisoru@ugal.ro
}

\author{
Costică Hogaș \\ "Dunarea de Jos" University of Galati, \\ Faculty of Naval Architecture, Galati, Domneasca \\ Street, No. 47, 800008, Romania, \\ E-mail: costica.hogas@glo-marine.com

\section{Costel Iulian Mocanu} \\ "Dunarea de Jos" University of Galati, \\ Faculty of Naval Architecture, Galati, Domneasca \\ Street, No. 47, 800008, Romania, \\ E-mail: costel.mocanu@ugal.ro
}

\begin{abstract}
Due to the Classification Societies' regulations, in the preliminary design stage for new ship constructions it is necessary to prove with calculations that the stress and deformation distributions in the ship structure do not exceed the stress limit values, regardless the sea state such as calm water, sagging or hogging wave conditions. Normally, it is considered that the hogging and sagging conditions are the worst head wave conditions, when the vertical shear forces and bending moments can reach high values and the risk of ship structure collapse can be high. The main purpose of this study is to assess, using the Finite Element Method (FEM), the global strength for a split hopper barge in three sea state conditions: calm water, hogging and sagging head design waves.
\end{abstract}

Keywords: hogging and sagging waves, global strength analysis, design waves, stress assessment.

\section{INTRODUCTION}

A split hopper barge is a special vessel, usually towed by a tug or with self propulsion which is used for hydro-technical, fluvial or maritime works, especially for dredges, the main purpose being to transport the dredged material.

The main purpose of this study is to determine the global stress and deformation distribution for such a vessel in the cases of calm water, hogging and sagging waves [1], [2],[3],[5]. To do this analysis we chose to use a vessel that is already built and fully functional. The main particulars of the split hopper barge are presented in Table 1.
Table 1. Main particulars of the barge

\begin{tabular}{|l|c|}
\hline Length over all, $L_{O A}[\mathrm{~m}]$ & 54 \\
\hline Length of waterline, $L_{W L}[\mathrm{~m}]$ & 52 \\
\hline Beam, $B[\mathrm{~m}]$ & 10 \\
\hline Depth, $H[\mathrm{~m}]$ & 3 \\
\hline Draft, $T[\mathrm{~m}]$ & 2 \\
\hline Volumetric displacement, $\nabla\left[\mathrm{m}^{3}\right]$ & 780 \\
\hline
\end{tabular}

Based on the construction plans, the 3D model of the ship was generated in Rhinoceros [9] from surfaces (Fig.1). To obtain accurate results from the analysis, every part of the barge structure was modelled. In order to reduce the amount of time that would take to generate the whole 3D model of the barge, only the fore pick up to the first strengthened 
frame was modelled. In this way, once the 3D model is ready, it can be imported in the finite element analysis software [4] where the mesh will be generated. Then the mesh elements and nodes for the rest of the structure are copied until we obtain the full 3D model. For this analysis FEMAP/NX Nastran [4] software is used.

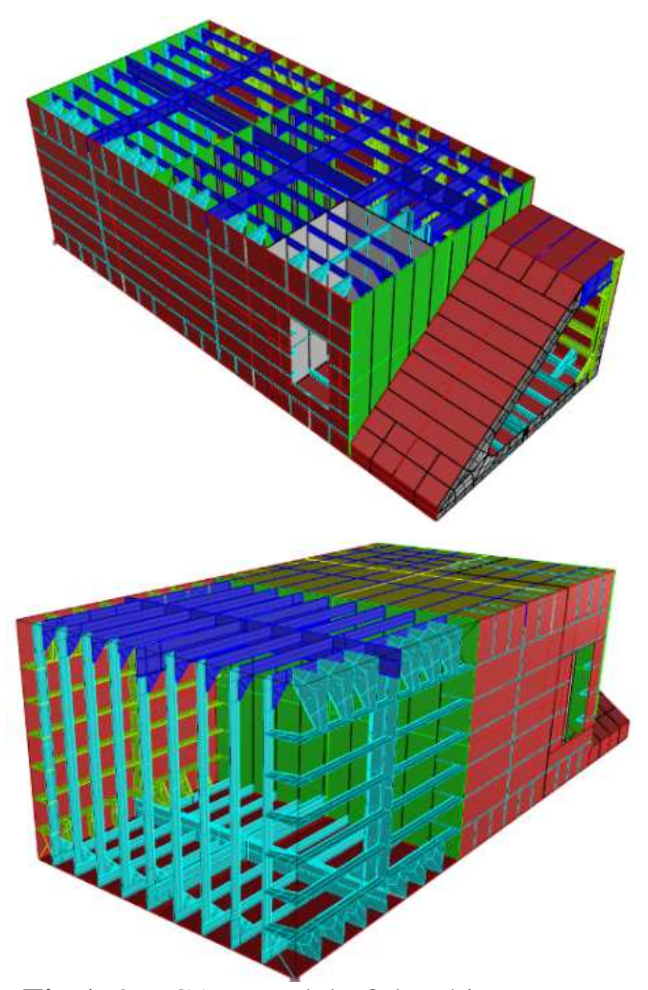

Fig.1. 3D-CAD model of the ship structure

In Fig. 1 it is presented the 3D-CAD model of the ship structure (using only surfaces) that was generated using Rhinoceros [9]. With the 3D-CAD model done, the .sat file is exported from Rhinoceros [9] and imported in FEMAP/NX Nastran [4]. The finite element analysis software allows us to generate the mesh directly on the surfaces. Because the model is very complex and the software does not recognise the intersection between two surfaces the mesh cannot be done automatically by the FEM software and needs to be made manually.

\section{EQUIVALENT DESIGN WAVE}

For a head design wave defined by height $h_{w}$ from rules [1],[2],[5] and length $\lambda=\mathrm{L}$, equal with the ship's length $L$ for maximum structural response, the quasistatic wave free-surface elevation is [3]:

$\zeta_{w}(x)=d_{p p}+\left(d_{p v}-d_{p p}\right) \frac{x}{L} \pm \frac{h_{w}}{2} \cdot \cos \left(\frac{2 \pi x}{\lambda}\right)$

where: $x \in[0, L] ; d_{p p}, d_{p v}$ are the barge design wave equilibrium parameters obtained by an iterative procedure [3]; \pm sagging or hogging wave condition.

The pressure from head design wave acting over the external shell of the 3D-FEM barge hull model has the expression [3]:

$$
p_{w}(x, z)=\rho \cdot g \cdot\left[\zeta_{w}(x)-z\right] ; z \in[0, H]
$$

where: $\rho, g$ are the water density and the gravity acceleration.

\section{BOUNDARY CONDITIONS}

The barge hull is symmetrical at the longitudinal central plane and including the control nodes at both extremities; the boundary conditions applied on the 3D-FEM model are presented in Table 2 and Fig.2.

Table 2. 3D-FEM boundary conditions [3]

\begin{tabular}{|l|c|c|c|c|c|c|}
\hline DOF & Ux & Uy & Uz & Rx & Ry & Rz \\
\hline Symm. plane & - & X & - & X & - & X \\
\hline Fore node & - & X & X & X & - & X \\
\hline Aft node & X & X & X & X & - & X \\
\hline
\end{tabular}

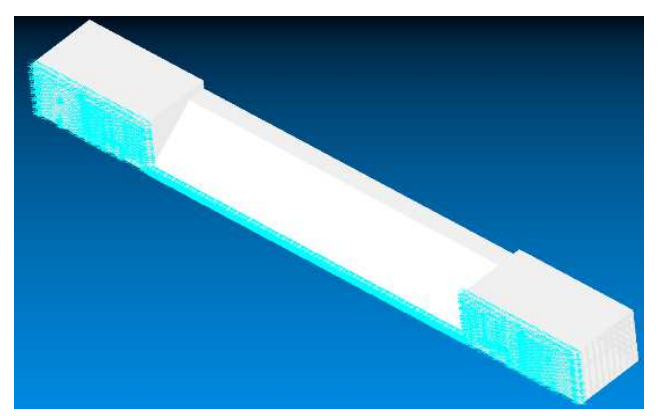

Fig.2. 3D-FEM model boundary conditions 


\section{THE 3D-FEM MESH}

The 3D-FEM model is developed using membrane and thick plate (Mindlin), triangle and quad, finite elements [6],[7],[8],[10]. The resulting FEM-mesh consists in 162400 finite elements and 149326 nodes (Fig.3).

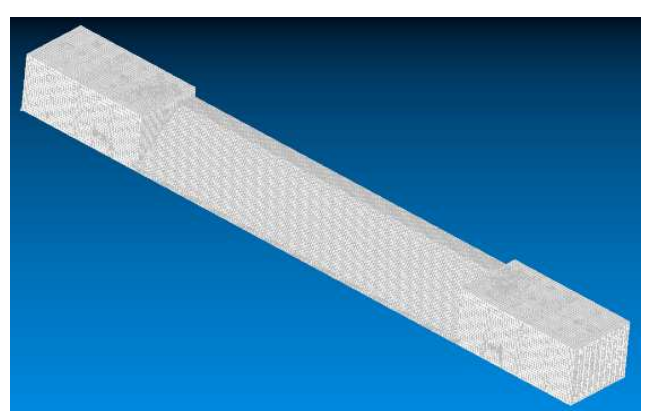

Fig.3. The 3D-FEM mesh model

\section{LOADS ON 3D-FEM MODEL}

To obtain a better perspective of the results we ran three different cases, i.e. when the ship is in calm water, in hogging and sagging conditions. For the analysis it is necessary to take into account the gravity load from all the model masses and to apply the external load induced by waves [3]. To apply the pressure correctly, the external shell finite elements have to be checked and oriented so that the normal vector on face 1 is going from the outside to the inside of the barge hull [4]. To apply the pressure on the external shell of the barge, the following expression was used [3]:

$$
\begin{aligned}
& \max (0.000 ;(1.05525 e-5 *(-Z E L(! E L)+ \\
& ! D P P+(! D P V-! D P P) * X E L(! E L) / ! L \pm \\
& \pm ! H W / 2 * C O S((2 * 180 * X E L(! E L)) ! ! L)))))
\end{aligned}
$$

where: $E L$ are the immerse elements; $H W=0$, $1.8 \mathrm{~m}$ is the wave height; $D P P=D P V=0.9611$ $\mathrm{m}$ are the barge - wave equilibrium parameters; $L=54 \mathrm{~m}$ is the barge overall length.

All the variables from equation (3) have been previous defined in FEMAP/NX Nastran [4]. Also for the entire 3D-FEM model the body gravity load is defined $a_{z}=-g=9.81 \mathrm{~m} / \mathrm{s}^{2}$ for weight modelling.
Case 1.

For the first case we have the external pressure distribution (3) when the ship is in the most frequent position, that is when the ship is on calm water $\left(h_{w}=0\right)$.

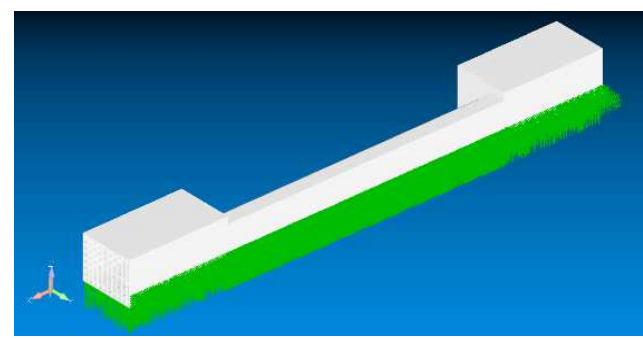

Fig.4. Calm water - pressure distribution

Case 2.

For the second case we have the external pressure distribution (3) when the ship is on hogging condition $\left(h_{w}=-1.8 \mathrm{~m}\right)$ and the deck is subjected to stretch and the bottom to compression.

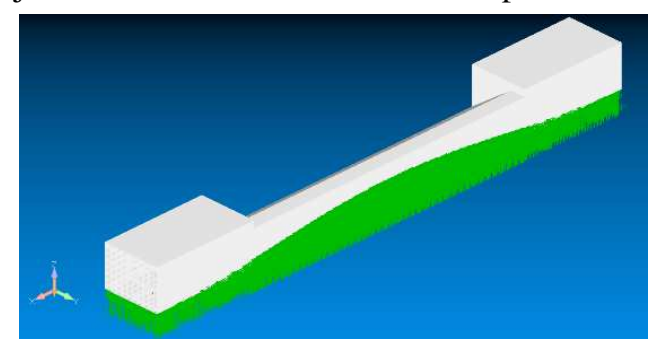

Fig.5. Hogging - pressure distribution

Case 3.

And for the third case we have the external pressure distribution (3) when the ship is on sagging condition $\left(h_{w}=+1.8 \mathrm{~m}\right)$ and the deck is subjected to compression and the bottom to stretch.

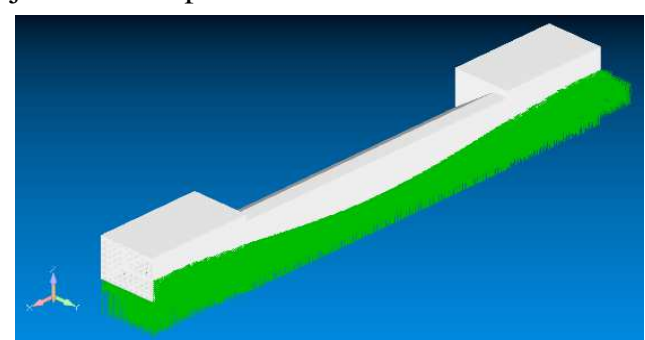

Fig.6. Sagging - pressure distribution 


\section{NUMERICAL RESULTS}

\section{Case 1.}

The maximum value for von Mises stress is around $200 \mathrm{MPa}$ for the full model (Fig.7). If we look just at the cargo area the values are much lower, somewhere around $55 \mathrm{MPa}$ (Fig.8). That high value is due to the transition to inclined deck where the structural elements of the barge structure are very complex.

Regarding the vertical displacement, we have a maximum value of $27 \mathrm{~mm}$ for the full model (Fig.9) and $27 \mathrm{~mm}$ for the cargo area (Fig.10), which means that the displacement remains constant and that the high value of the stress does not affect the barge deformation.

As we can see the maximum value of the vertical displacement is located somewhere around the central line of the ship, as it was expected. The most affected part is the shell of the barge bottom, due to the water pressure acting on the barge's shell.

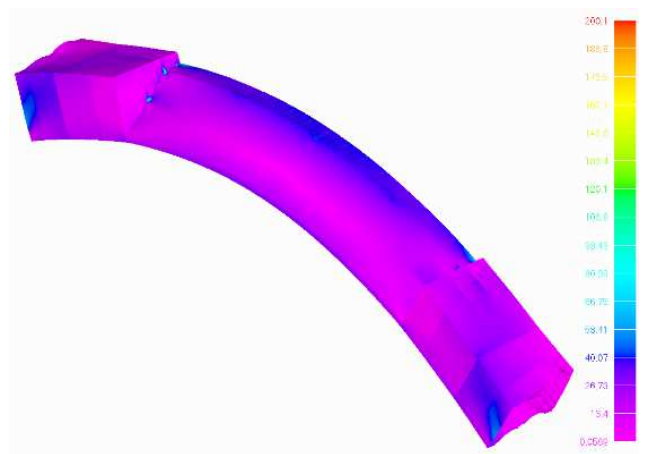

Fig.7. Case 1-Stress distribution - full model

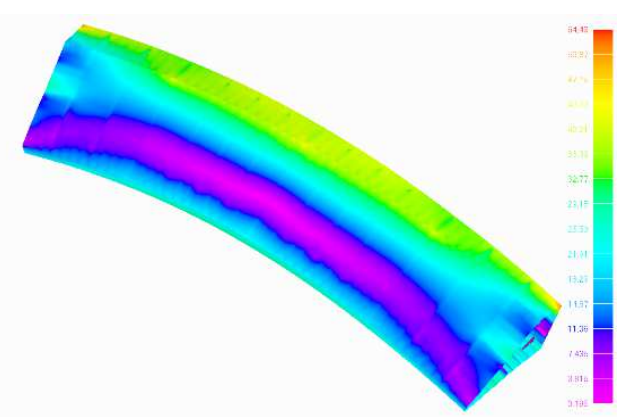

Fig.8.a Case 1-Stress distribution - cargo area

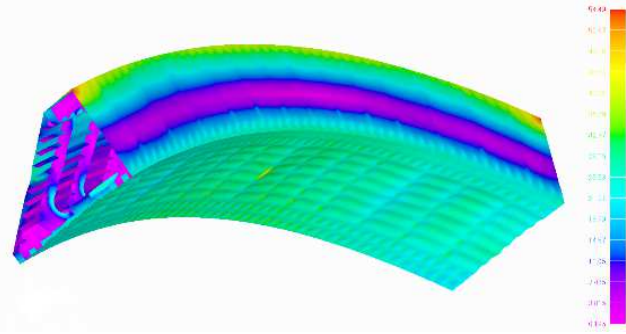

Fig.8.b Case 1-Stress distribution - cargo area

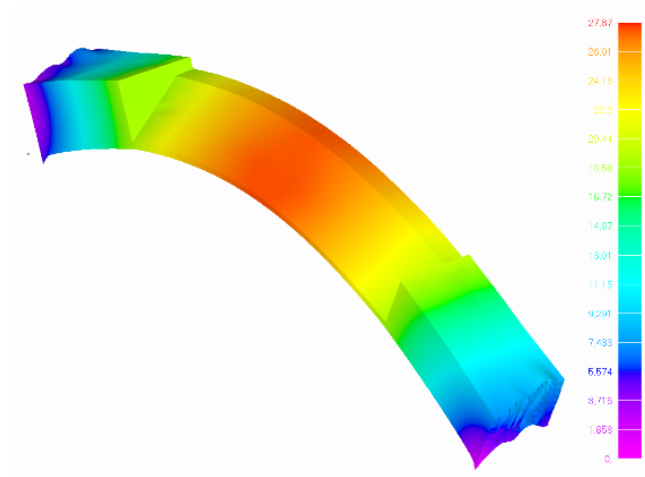

Fig.9.Case 1-Vertical displacement - full model
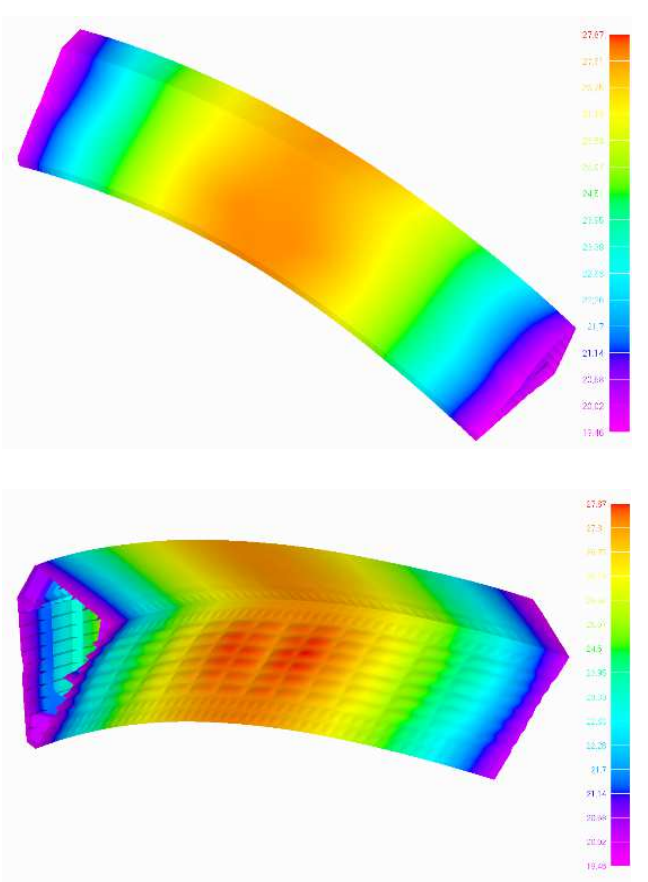

Fig.10. Case 1-Vertical displacement-cargo area 


\section{Case 2.}

As it was expected, the vertical maximum displacement is located within the same area, but the values are a little higher this time, some-where around $42 \mathrm{~mm}$ (Figs.13,14).

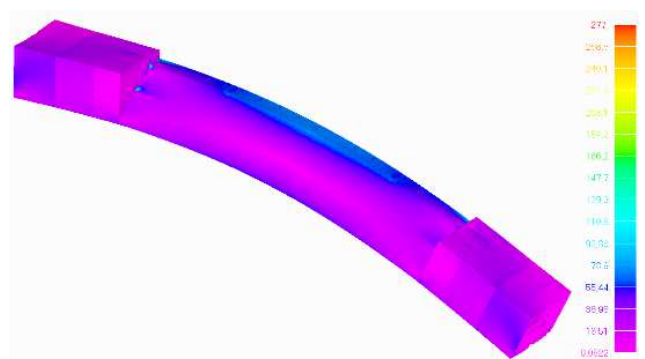

Fig.11. Case 2 - Stress distribution - full model
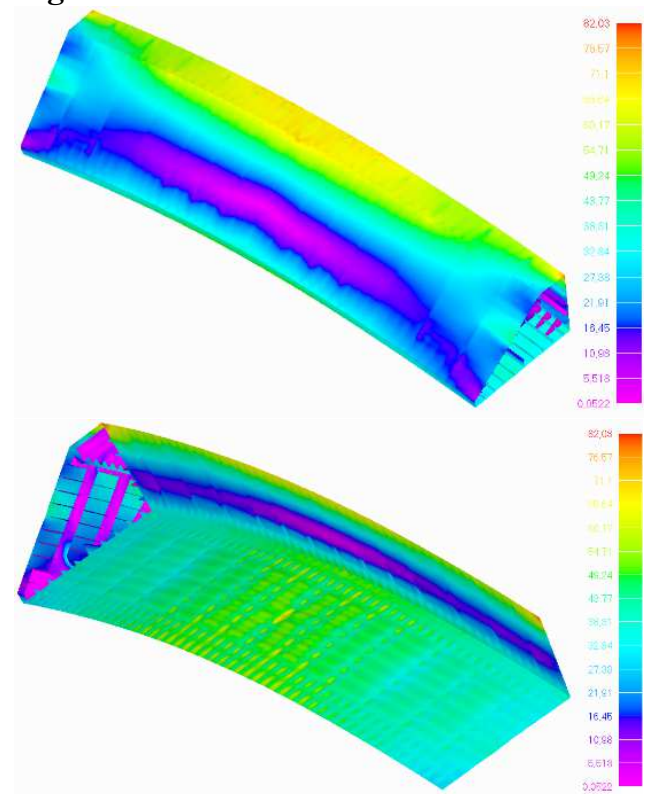

Fig.12 Case 2 - Stress distribution - cargo area

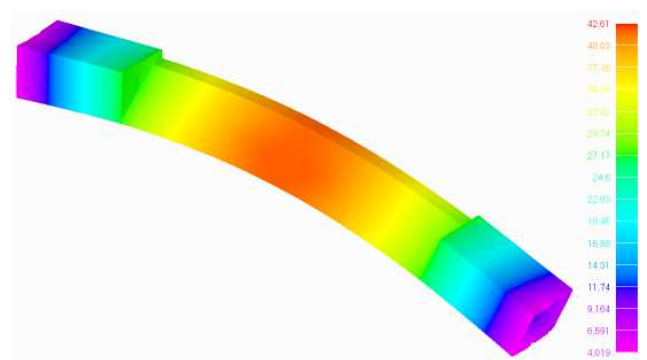

Fig.13. Case 2 - Vertical displacement-full model
For the hogging condition the structure behaviour is similar to the calm water condition, but for this case the maximum stress value is around $277 \mathrm{MPa}$ (Figs.11,12). This is also due to some stress concentrators.
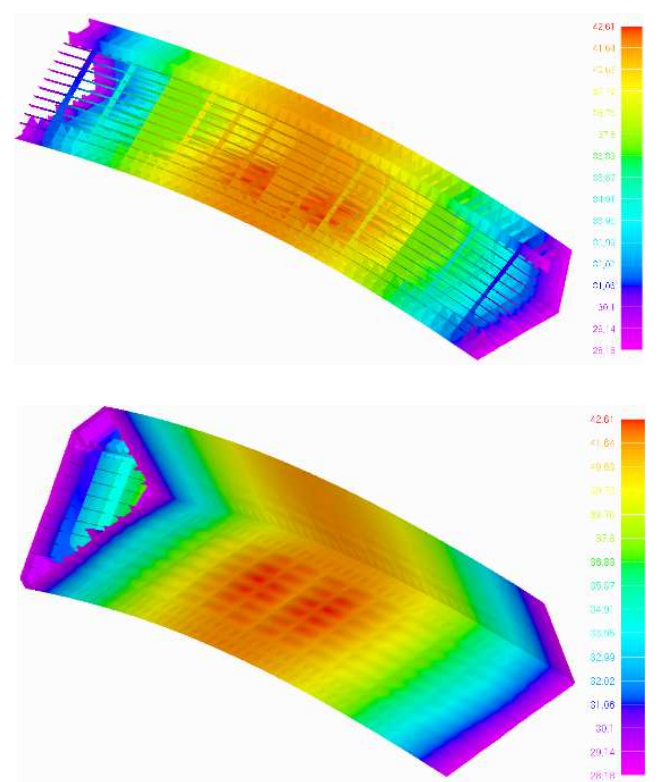

Fig.14. Case 2 -Vertical displacement - cargo area

\section{Case 3.}

For the third case the maximum value for Von Mises stress is $123 \mathrm{MPa}$ (Fig.15). This means that the structure response for sagging condition is better than in the other two cases. Also, for the cargo area, the stress value is $29 \mathrm{MPa}$ (Fig.16).

Similarly, the vertical displacement for the sagging condition has the lowest value, somewhere around $13 \mathrm{~mm}$ (Figs.17.18).

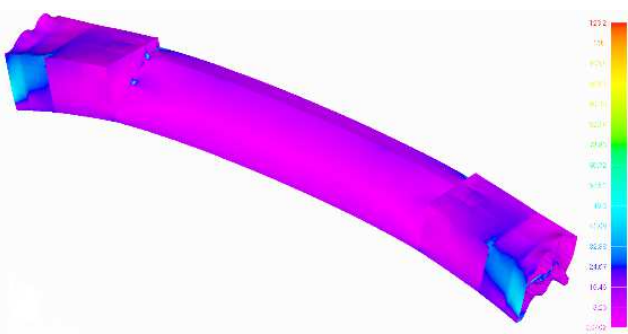

Fig.15 Case 3 - Stress distribution - full model 


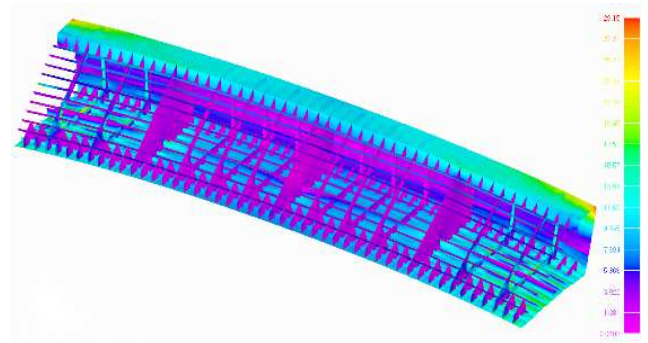

Fig.16. Case 3 - Stress distribution - cargo area

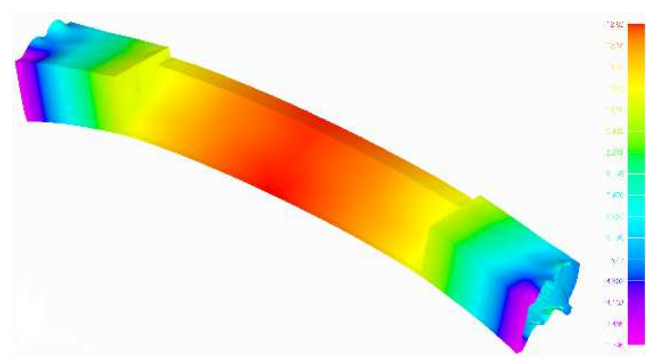

Fig.17. Case 3 - Vertical displacement-full model

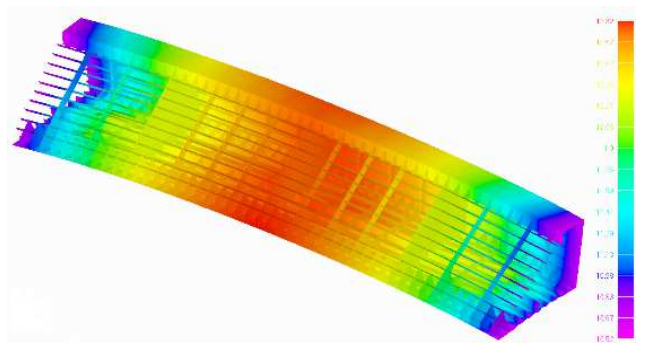

Fig.18. Case 3 - Vertical displacement-cargo area

\section{CONCLUSIONS}

Using the FEM finite element method, the global strength for a split hopper barge in the design stage has been performed. As it was shown in this study, we can analyse the structural behaviour of the barge in terms of equivalent von Mises stress and the maximum displacement distributions, so we can assess the integrity of the barge by the rules criteria [1],[2].

Taking into account that the von Mises stress does not exceed the rules' admissible value in the central area, and the highest value corresponds to a local effect, we can conclude that the structure is overall welldimensioned, and some local redesign is required to reduce the stress hot spots.
Table 3. 3D-FEM numerical results

\begin{tabular}{|c|c|c|c|}
\hline \multicolumn{4}{|c|}{ Full model results } \\
\hline Case & $\begin{array}{c}\text { Calm } \\
\text { water }\end{array}$ & Hogging & Sagging \\
\hline $\begin{array}{c}\text { VonMises } \\
\text { stress [MPa] }\end{array}$ & 200.1 & 277 & 132.2 \\
\hline $\begin{array}{c}\text { Displacement } \\
{[\mathrm{mm}]}\end{array}$ & 28.87 & 42.61 & 12.82 \\
\hline
\end{tabular}

\begin{tabular}{|c|c|c|c|}
\hline \multicolumn{4}{|c|}{ Central area results } \\
\hline Case & $\begin{array}{c}\text { Calm } \\
\text { Water }\end{array}$ & Hogging & Sagging \\
\hline $\begin{array}{c}\text { VonMises } \\
\text { stress [MPa] }\end{array}$ & 54.49 & 82.03 & 29.15 \\
\hline $\begin{array}{c}\text { Displacement } \\
{[\mathrm{mm}]}\end{array}$ & 27.87 & 42.61 & 12.82 \\
\hline
\end{tabular}

\section{Acknowledgements}

The research was supported by the Naval Architecture Faculty, from "Dunarea de Jos" University of Galati, which is greatly acknowledged.

\section{REFERENCES}

[1]. BV, “Rules”, Bureau Veritas, Paris, 2019.

[2]. DNV-GL, "Rules", Det Norske Vertias Germanischer Lloyd, 2019.

[3]. Domnisoru, L., "Structural analysis and hydroelasticity of ships", The University Foundation "Dunarea de Jos" Publishing House, Galati, 2006.

[4]. FNN, "Femap/NX Nastran Users' Manual", Siemens PLM Software Inc., 2019.

[5]. ISSC, "Proceeding of the 20th ISSC Congress", IOS Press, Amsterdam, 2018.

[6]. Mocanu, C.I., "Strength of materials", "Dunarea de Jos" University Foundation Publishing House, Galati, 2005.

[7]. Nastasescu, V., "Finite element method", Military Technical Academy Publishing House, Bucharest, 1995.

[8]. Rao, S.S., "The finite element method in engineering”, Elsevier Science \& Technology Books,, New York, 2004.

[9]. Rhino, "Rhinoceros Users' Manual”, Robert McNeel \& Assoc., 2019.

[10]. Zienkiewicz, O.C., Taylor, R.L.," The finite element method", (3 Volumes), Elsevier Butterworth-Heinemann, Oxford, 2000.

Paper received on August $20^{\text {th }}$, 2019 